\title{
Ubiquitous Energy Storage
}

\author{
C. E. T. Foote, Member, IEEE, A. J. Roscoe, R. A. F. Currie, G. W. Ault, Member, IEEE, J. R. \\ McDonald, Fellow, IEEE
}

\begin{abstract}
This paper presents a vision of a future power system with "ubiquitous energy storage", where storage would be utilized at all levels of the electricity system. The growing requirement for storage is reviewed, driven by the expansion of distributed generation. The capabilities and existing applications of various storage technologies are presented, providing a useful review of the state of the art. Energy storage will have to be integrated with the power system and there are various ways in which this may be achieved. Some of these options are discussed, as are commercial and regulatory issues. In two case studies, the costs and benefits of some storage options are assessed. It is concluded that electrical storage is not cost effective but that thermal storage offers attractive opportunities.
\end{abstract}

\section{Index Terms - distributed energy resources, energy storage}

\section{INTRODUCTION AND BACKGROUND}

$\mathrm{T}$ HE pursuit of cleaner and more efficient electrical energy coupled with changes in commercial and regulatory structures in the electricity industry is leading to an expansion in the amount of distributed generation (DG) - small and renewable sources connected throughout the system. This expansion presents a number of challenges, one of the most significant being the second by second balancing of system supply and demand. A potential solution to this challenge of mismatched supply and demand is increased use of energy storage in the electricity system. Energy storage technologies range from small-scale uninterruptible power supplies to largescale hydroelectric pumped storage schemes. The further development of these technologies is the subject of widespread research in industry and academia across the world.

This paper presents a vision of a future power system where storage is everywhere, as illustrated in Fig. 1. The term "ubiquitous energy storage" [1] is adopted to describe energy storage being deployed and utilized at all levels of the electricity system, from small batteries in appliances or heat storage in domestic combined heat and power, through battery and fuel cell based storage on the distribution system, to the greater utilization of large-scale storage on the transmission system.

The potential impact of ubiquitous energy storage on electricity networks must be explored. This paper contributes to this discussion by presenting the main issues and through examples, showing how alternative storage options can be

C. E. T. Foote (c.foote@eee.strath.ac.uk), A. J. Roscoe (ajroscoe@eee.strath.ac.uk), R. A. F. Currie (rcurrie@eee.strath.ac.uk), G. W. Ault (g.ault@eee.strath.ac.uk) and J. R. McDonald (j.mcdonald@eee.strath.ac.uk) are all with the Institute for Energy and Environment at the University of Strathclyde, Glasgow, UK assessed. The case studies are used to compare the costs and benefits of energy storage and lead to conclusions on the costeffectiveness of the ubiquitous energy storage concept.

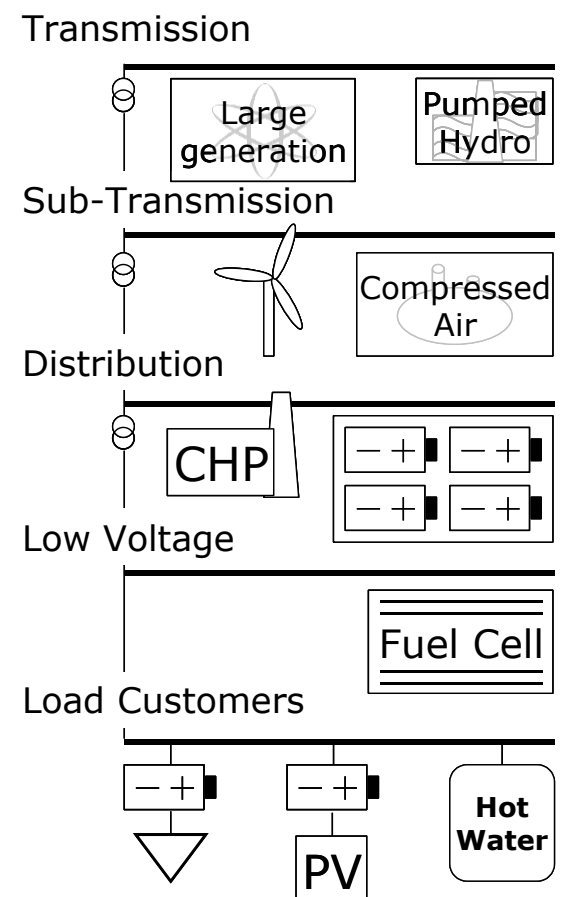

Fig. 1. Future power system with ubiquitous energy storage

\section{STORAGE REQUIREMENTS}

The need for storage in the electricity system is driven by a number of factors:

- The integration of new energy sources, particularly renewables, with intermittent output and capacity factors much lower than conventional sources

- The expense, financially and in terms of emissions, of maintaining a "spinning reserve" to react to changes in electricity demand

- The connection of generation to weak or congested networks and the reluctance of the public to accept expansion of the transmission and distribution infrastructure

- A desire for improved security, particularly for some industrial and critical-load customers, facilitated through local supply and modularization of the electricity system

- The opportunities for economic optimization of energy demand in a market structure with time-varying prices

Ubiquitous energy storage would facilitate the leveling of power flow profiles, facilitating an increase in network utilization. Transmission and distribution infrastructure would 
be designed to accommodate the average power demand rather than the peak. The time-dependency of electricity supply would be dramatically reduced, improving reliability and security of supply and leading to lower overall prices.

\section{Storage CAPABILITIES AND EXISTING APPLiCATIONS}

The capabilities of different storage technologies are constantly being upgraded by ongoing development. The recognition of storage as an important enabling technology in future power systems has led to a number of reviews and studies, including [2]-[4]. The main storage technologies are summarized below.

- Pumped hydro capacity in the UK is currently $14 \mathrm{GWh}$, with a maximum power of $\sim 2788 \mathrm{MW}$, equating to $\sim 5 \%$ of UK peak load for 4-5 hours. Schemes can be brought on line within seconds if "spinning in air" or minutes from a standing start. The addition of further large-scale pumped-hydro schemes in the UK is unlikely due to the lack of suitable sites, coupled with environmental and planning constraints which lead to uncertainties in cost and lead time. The energy density is also poor. Smaller schemes based upon head heights of $30 \mathrm{~m}$ could release $\sim 0.08 \mathrm{kWh}$ per $\mathrm{m}^{3}$ of water, at a round-trip efficiency of $\sim 70 \%$.

- Battery storage via a power electronic interface offers very fast response times, relatively high energy densities $(\sim 30 \mathrm{kWh} / \mathrm{m} 3)$, and relatively good round-trip efficiencies $(\sim 85 \%)$. The downsides are the relatively high cost $(\sim \$ 100 / \mathrm{kWh}$ for lead-acid and $\sim \$ 200 / \mathrm{kWh}$ for dry cell types), the requirement for both the purchase and safe disposal/reprocessing of large amounts of heavy metals, and the limited number of deep charge cycles (100-200) that each battery can undergo before replacement or refurbishment. Battery schemes are currently viable only in key locations to support infrequent power and frequency requirements within fragile or islanded networks. In such applications they are an excellent fit as the power can be dispatched within milliseconds and over reasonably wide power ranges limited only by the power interface limits and the battery current/thermal considerations.

- Electrochemical fuel cells using reversible REDOX reactions offer similar properties to lead-acid batteries, but with lower usage of heavy metal electrodes, more deep charge cycles, but higher complexity.

- A hydrogen electrolysis/fuel-cell storage system offers by far the greatest energy density of all storage types, with a releasable electrical energy of about $800 \mathrm{kWh} / \mathrm{m}^{3}$. However, the round trip electrical efficiency is very poor $(\sim 20 \%)$, with about another $20 \%$ recoverable as heat if a local use can be found. There are several different fuel cell technology types, operating at different temperatures and using different liquid or solid electro-chemical processes. The technology is relatively immature and developments may occur which improve the controllability, reliability, and economic viability of the cells. At present, realizable costs of large or small-scale implementations are not yet well understood; neither are the lifetime and reliability which are both heavily compromised by many factors including rapid power ramps and fuel contamination. Power output ramp rates are severely limited for some fuel cell types. For example, achieving $100 \%$ output from a large $250 \mathrm{~kW}$ Solid-Oxide Fuel Cell (SOFC) after a cold-start could take 9-12 hours. Some fuel cells also become unstable below $40 \%$ rated output power which additionally limits the controllability. A solution to these problems might be to combine fuel cells with either batteries or flywheels which could cope with the most rapid power fluctuations.

- Compressed air storage has been successfully implemented in several disused salt caverns, requiring geologically sound chambers with volumes between 250,000 and $500,000 \mathrm{~m}^{3}$, several hundred meters below ground, at a working pressure of $75-100$ bar. The releasable energy density is poor at $1-2 \mathrm{kWh} / \mathrm{m}^{3}$, and the round-trip efficiency is limited due to thermal losses from the high temperature pressurized air unless heat can be extracted and recycled during the charging process. The isentropic efficiencies of the compressor and generator turbines are also limits. Future focus would need to be upon smaller man-made reservoirs due to the lack of suitable sites for large schemes. Capital cost for a small scheme is estimated at $\sim \$ 200 / \mathrm{kWh}$ of storage capacity.

- Flywheel technologies offer low energy storage density $\left(<12 \mathrm{kWh} / \mathrm{m}^{3}\right)$, at a high cost $(\sim \$ 6000 / \mathrm{kWh}$ or more $)$, and a relatively low round-trip efficiency over periods of time due to bearing and windage losses ( $>1 \%$ loss per hour). However, the entire recoverable electrical energy can be released over periods as short as ten seconds, which can make the cost per $\mathrm{kW}$ and power density more favorable than batteries for short-term UPS activities which are only required to maintain power until a backup generator comes online [10]. This is a niche market for flywheel technologies, and it is unlikely that they can become competitive in bulk long-term energy storage.

- Superconducting energy storage is orders of magnitude more expensive again than flywheel technologies, and offers even less dense energy storage. It offers extremely quick high-power energy release over sub-second timeframes for extremely specialized and sensitive load applications.

- Storage of heat offers the most cost-effective form of embedded storage, although the applications are limited to locations where the heat can be effectively used within suitable timeframes (a few days at most for domesticscale applications). Storage of hot water on domestic premises can be achieved at a cost of $\$ 25 / \mathrm{kWh}$ or less with an energy density of $\sim 65 \mathrm{kWh} / \mathrm{m}^{3}$, using a well insulated hot water tank of $\sim 0.4 \mathrm{~m}^{3}$ capacity coupled with an immersion heater element or a CHP boiler. The technology is simple and conventional, and can be 
integrated with existing central heating systems. The system is most effective in winter when heat losses from the tank to the dwelling can offset other heating requirements if the tank is suitably located within the dwelling.

Existing examples show that energy storage is used for a number of applications but its greater use in bulk energy storage is limited by technology, efficiencies and ultimately cost. However, future power systems will utilize storage more widely as the balance of costs and benefits shifts in favor of storage. This shift will be driven by the increasing attractiveness of renewable energy, which will require storage to expand beyond a certain level, a continuing reluctance to accept large and intrusive transmission and distribution infrastructure, a growing desire for security facilitated through local supply and modularization of the electricity system, and improvements in the capabilities and efficiencies of storage technologies.

\section{INTEGRATION AND CONTROL OF STORAGE}

The widespread integration of storage in electricity networks would require a number of important issues to be addressed. Most of these also arise with the integration of DG and include risks associated with reverse energizing of the network and the effect on protection. Ubiquitous energy storage will comprise many different types of storage technology being used for multiple purposes at different levels of the electricity system. Thus, the integration and control of storage will require an array of methods. Some of the possible approaches to control are discussed below and some are explored further in the case studies.

- Autonomous, intelligent control of small storage and controllable loads would offer some advantages without incurring all the overheads of communication. With appropriate intelligent systems methods, storage units could learn the load profiles of supported loads so that the storage can start charging in advance and thereby smooth the load peak over a longer period of time [5]. With sufficient storage capacity, intelligent control would not be necessary. A flat profile could be produced by constant charging of a storage unit large enough to handle any variations in load.

- Coordinated control of storage resources within a microgrid or other managed segment of the grid would provide an opportunity to optimize energy management while satisfying grid constraints [9]. This would require some communication between separate resources although control could be distributed or centralized.

- A number of projects and publications have examined the possibility of hybrid wind-storage or PV-storage systems. These are designed to enhance the controllability of the intermittent renewable resource to maximize revenue in the energy market, maintain supply to a load, or reduce the required grid connection capacity [8].

- Storage facilities could be installed in distribution substations to smooth the load profile, provide enhanced security, and reduce the required feeder capacity for various scenarios of generation and load. Different control approaches are possible but larger facilities are likely to come under the control of the distribution network control room. Operators would be able to adjust the operation of the storage facility according to local conditions.

- Large-scale storage connected at the transmission level could be programmed to provide automatic frequency response or else be set to operate in conjunction with carbon-free generation. However, such large storage facilities will offer the opportunity for lucrative participation in electricity markets and as such are likely to have human operators directing their use.

- The real-time market price for electricity could be used to trigger buy/sell (charge/discharge) decisions. This could occur at the domestic level if real-time pricing was passed on to these consumers. The pricing signal would not only control storage, but also demand-response via demand elasticity. Demand response can be considered as a form of storage with an efficiency of $>=100 \%$ if loads are shifted in time (i.e. a washing machine cycle is delayed) or curtailed completely (i.e. a lighting load is reduced). Real-time prices might need to be calculated on a regional or zonal basis, taking into account local transmission or distribution system constraints and power flows. An important consideration when using price as a control signal is that profitability of storage implementation will depend upon the differential between buy and sell prices at the charge and discharge times. As more storage (and/or demand response) is implemented, the load curves will be flattened and the buy/sell price differentials will tend to be reduced. This will place a natural limit upon the amount of storage that can be profitably installed in the network.

The basis for such control systems is likely to emerge as DG becomes more widespread and it becomes necessary to coordinate the control of tens of thousands of generation sources. Such integrated control could be the subject of future research.

\section{COMmerCial AND Regulatory IsSUes}

The commercial and regulatory issues associated with DG are still being resolved and the outcomes are likely to be different in different places. For example, the participation of DG in energy markets presents a range of challenges and different solutions are available [6]. Ubiquitous energy storage would present a similar, perhaps even more complicated, set of challenges.

Storage might be viewed both as a consumer and producer of power, thereby participating in the market as both a load and generator. Alternatively, storage might be viewed as an integral part of the distribution network, thereby removing it from the normal energy market. This might be linked to the question of who owns storage: load customers, generators, independent storage operators, or the network operator. 
Regulation concerning the separation of roles in the electricity system varies from place to place and the ownership and operation of storage will vary as a consequence.

\section{CASE STUdiES}

The deployment of ubiquitous energy storage will require detailed analysis of the technical implications as well as an economic assessment of the costs and benefits. The case studies presented here demonstrate how storage might be used in future power systems and how different control methods will be used in different circumstances.

\section{A. Case Study A-Economic simulation based upon real-time pricing in the marketplace}

This case study was carried out using a demand-response analysis tool [2], focusing on a future scenario in which a population's behavior is unchanged, but the presence of ubiquitous storage enables "peak clipping" and "valley filling". In the scenario, $15 \%$ of households heat their homes and water with electricity; while $70 \%$ of households use gas (UK 2003 levels [11]). Two simulations are run; a baseline simulation using fixed price electricity, and then a simulation including storage effects that are triggered by real-time pricing signals. In the first simulation, all the electrically heated homes have convection heaters for space-heat and small 120 liter immersion tanks equipped with $3 \mathrm{~kW}$ heater elements that activate just in time to heat water which satisfies hot-water demands. Thus there is negligible energy stored in hot water tanks. Also, there is no battery storage included.

The conventional thermal generation capacity is fixed at $80 \%$ of the peak demand for this first baseline simulation, with a further $40 \%$ of the peak demand capacity provided by wind generation. This does not guarantee that demand is always met, so there are periods of blackout expected in the simulation (Fig. 3). The simulations analyze a single year period, from midsummer to midsummer using realistic weather and load data to simulate industrial, commercial and domestic loads [2], [7]. Domestic loads are disaggregated into heating, cooking, lighting, wet, cold, and brown appliance types. These loads are simulated on a quantized house-by-house basis simulating a diversity of customers, responding to changes in weather and time of day/week. The match of supply and demand determines real-time price, using a price model empirically determined from recent UK wholesale price behavior [2]. The capacity and demand in this first simulation results in a sustainable fixed price of $10 \mathrm{p} / \mathrm{kWh}$ for electricity at residential load delivery points.

In the storage-modified simulation, the generation portfolio is the same, but $50 \%$ of the electrically heated homes use larger hot water tanks (400 liter capacity). The heater element is still $3 \mathrm{~kW}$, so the tanks take up to 10 hours to heat up from a cold start. The "effective" energy storage is about $18.5 \mathrm{kWh}$ per installation, based upon a maximum temperature of $75 \mathrm{C}$ and a minimum temperature of $35 \mathrm{C}$. Also, in the second simulation, $10 \%$ of the households possess battery storage with $15 \mathrm{kWh}$ capacity. Each installation can store or release power at a rate of $1 \mathrm{~kW}$, giving a charge or discharge time of 15 hours.

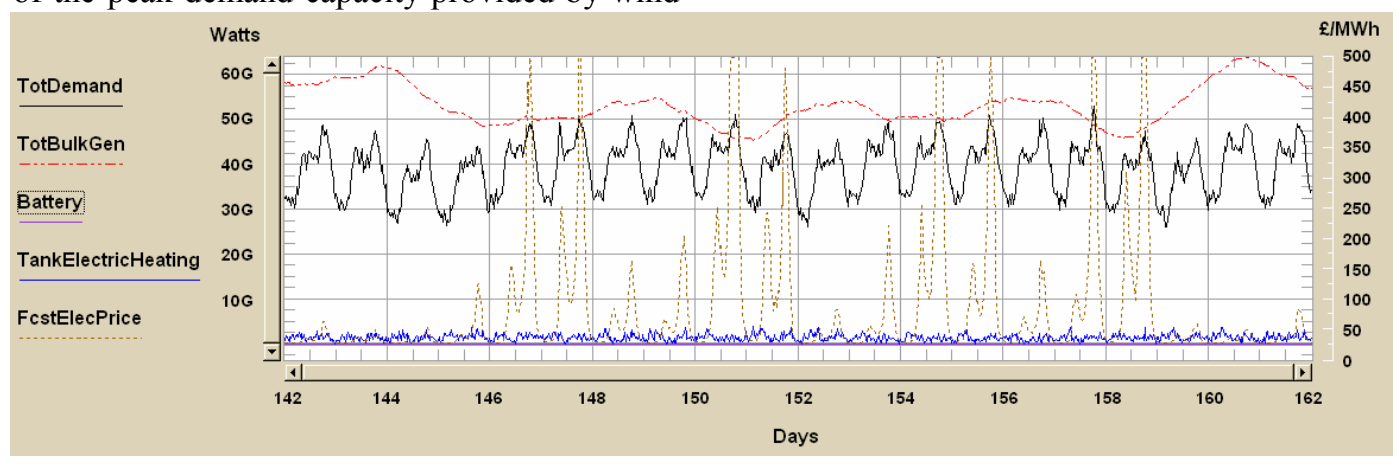

Fig. 2. Baseline simulation, showing demand rising above capacity

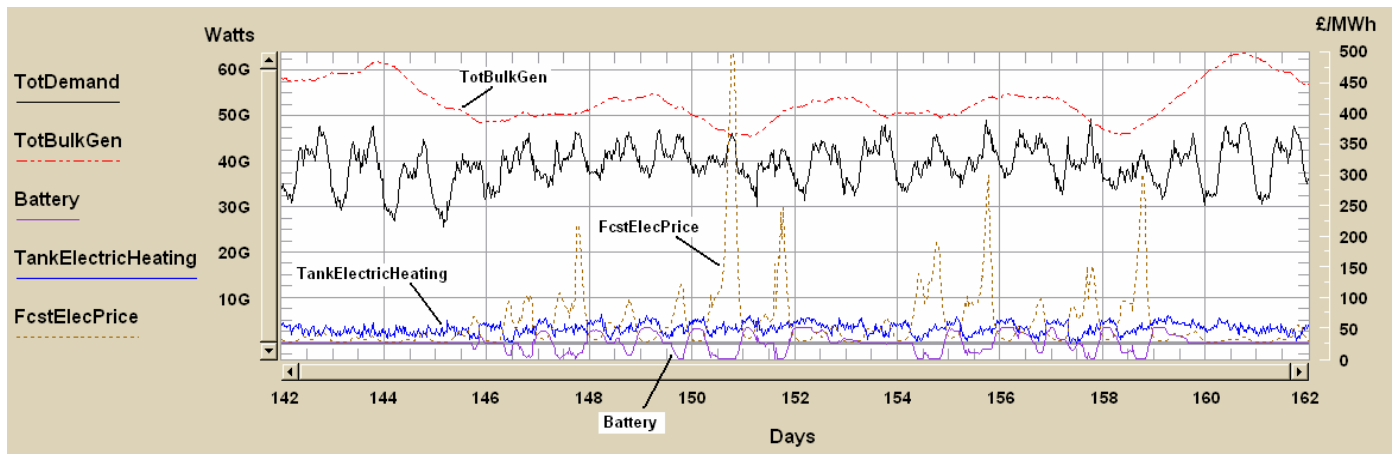

Fig. 3. Storage-modified simulation with ubiquitous storage, showing modified demand profile to match supply capacity more closely 
Power demand not met over the year can be expressed as a percentage of the overall annual electricity demand. This figure drops from $0.12 \%$ in the baseline simulation, to $0.04 \%$ in the storage-modified simulation (Fig. 4).

The results of the simulations show that the houses equipped with battery storage succeed in making, on average, $£ 0.29$ per day revenue, or $£ 105$ over the entire year due to energy "trading". The revenue per day varies between about $£ 0.44$ per day in winter and $£ 0.18$ in summer, due to the larger and more frequent price deviations in winter. Assuming an approximate initial capital cost for the battery system of $\$ 100$ per $\mathrm{kWh}$, the payback period of the storage system would be of the order of 8-10 years, neglecting any discount rate effects. Batteries may need to be replaced after a few years, however, threatening the viability of such a scheme.

Table I shows that even houses without the hot water storage are $£ 286$ better off over a single year period in the storage-modified simulation than the first. This is due to the implementation of real-time pricing and the mitigating effect of the heat and battery storage, which flattens the load profile and stabilizes the price fluctuations. However, households implementing hot water storage benefit from an additional $£ 462-£ 286=£ 176$ savings over the year. Assuming a cost estimate of $£ 1000$ for a larger hot water tank installation, payback could be over periods of roughly 6 years neglecting discount rate effects. This might be viable, considering that lifetimes of water tanks are substantially longer than 6 years and that they are generally maintenance-free.

TABLE I

COSTS AND SAVINGS ON SPACE AND WATER HEATING COSTS DUE TO HOT

\begin{tabular}{|c|c|c|c|c|}
\hline \multicolumn{5}{|c|}{ WATER STORAGE OVER ONE YEAR } \\
\hline & \multicolumn{2}{|c|}{$\begin{array}{c}\text { House without active hot } \\
\text { water storage }\end{array}$} & \multicolumn{2}{|c|}{$\begin{array}{l}\text { House with active hot } \\
\text { water storage }\end{array}$} \\
\hline & $\begin{array}{l}\text { Convection } \\
\text { heating }\end{array}$ & $\begin{array}{c}\text { (Small) } \\
\text { water tank } \\
\text { heating }\end{array}$ & $\begin{array}{l}\text { Convection } \\
\text { heating }\end{array}$ & $\begin{array}{c}\text { (Large) } \\
\text { water tank } \\
\text { heating }\end{array}$ \\
\hline $\begin{array}{l}\text { Simulation } 1 \\
\text { (Baseline) }\end{array}$ & $£ 622$ & $£ 449$ & $£ 622$ & $£ 442$ \\
\hline $\begin{array}{c}\text { Simulation } 2 \\
\text { (Storage-modified) }\end{array}$ & $£ 500$ & $£ 285$ & $£ 0$ & $£ 602$ \\
\hline Difference & $-£ 122$ & $-£ 164$ & $-£ 622$ & $+£ 160$ \\
\hline $\begin{array}{l}\text { Saving, simulation } 2 \\
\text { relative to simulation } 1\end{array}$ & \multicolumn{2}{|c|}{$£ 286$} & \multicolumn{2}{|c|}{$£ 462$} \\
\hline
\end{tabular}

B. Case Study B - Distribution Network Storage Enabling Increased Renewable Generation Connections

Connection to distribution networks can lead to operating constraints being imposed on renewables and DG, leading to reduced output and lost revenue. This case study examines two alternatives to network reinforcement for gaining access to constrained energy: battery storage and a hydrogen/fuel cell storage system with electrolyser. A techno-economic analysis of each option is performed to determine the option with the shortest payback period. The analysis considers the extension of an existing wind farm beyond the capacity available for power export from $10 \mathrm{MW}$ to $15 \mathrm{MW}$. The viability of each storage option will be compared to reinforcing the network to harness the additional 5MW.

The capital cost (Cc) of each storage option, network reinforcement and the wind energy installation was identified from a review of current state of the art [12] and previous work undertaken by the authors [13]. This review also addressed the technical elements of each system and allowed the annual MWh produced in each case to be calculated through the identification of system efficiencies.

The MWh generated by the wind farm is based on a capacity factor of $28 \%$. A value for Cc of $470 £ / \mathrm{MW}$ for the wind farm was used, combined with an annual operation and maintenance $(\mathrm{O}+\mathrm{M})$ cost of $4.7 £ / \mathrm{MW}$. The $\mathrm{Cc}$ for grid reinforcement used in the analysis is $441,176 £ / \mathrm{MW}$; with a $25 \%$ capitalized charge for $\mathrm{O}+\mathrm{M}$ plus $9 \%$ for utility profit. The rating of the battery storage device (with converter) is $2 \mathrm{MW}$, with a round trip efficiency of $89 \%$, capable of supplying 20MWh. The fuel cell is a $2 \mathrm{MW}$ Proton Exchange Membrane Fuel Cell (PEMFC), with a round trip efficiency of $40 \%$. The PEMFC system also includes hydrogen storage, a converter and a $2 \mathrm{~kW}$ electrolyser with an efficiency of $75 \%$. An $8 \%$ interest rate is incorporated within the analysis of the two storage options. The annual profit is calculated assuming $£ 60 / \mathrm{MWh}$ for revenue from energy sales and renewable energy certificates. This value is based on the UK Government's Renewables Obligation program. The $\mathrm{Cc}$ and $\mathrm{O}+\mathrm{M}$ costs shown in Table II for each option include the cost of the $5 \mathrm{MW}$ wind farm.

TABLE II

ECONOMIC VIABILITY OF STORAGE OPTIONS VS NETWORK REINFORCEMENT

\begin{tabular}{|c|c|c|c|c|}
\cline { 2 - 5 } \multicolumn{1}{c|}{} & $\begin{array}{c}\mathrm{Cc} \\
(£ \mathrm{k})\end{array}$ & $\begin{array}{c}\mathrm{O}+\mathrm{M} \\
(£ \mathrm{~K})\end{array}$ & $\begin{array}{c}\text { Revenue } \\
(£ \mathrm{k})\end{array}$ & $\begin{array}{c}\text { Payback } \\
\text { Period } \\
(\text { years })\end{array}$ \\
\hline Network Reinforcement & 5332 & 24 & 713 & 9 \\
\hline 2MW Battery (89\%) & 3529 & 230 & 634 & 17 \\
\hline 2MW PEMFC (40\%) & 9832 & 993 & 285 & Not viable \\
\hline
\end{tabular}

It is likely that additional costs will be incurred that are not included in this analysis, such as replacement costs and those relating to technical complexity and safety. The costs are scaled up from those identified for smaller projects but it could be that the $f / \mathrm{MW}$ cost could come down as projects are scaled up. Table II shows that the network reinforcement option provides the best payback period of 9 years. The battery storage option results in a 17-year payback period mainly due to the high annual operation and maintenance costs. The PEMFC fuel cell system is not economically viable at current cost levels.

The high $\mathrm{O}+\mathrm{M}$ costs associated with the storage options are a major barrier to the deployment of such technologies. The battery has a lower $\mathrm{Cc}$ than the network reinforcement but is not as economical due to annual $\mathrm{O}+\mathrm{M}$ costs and low efficiency. The PEMFC has the highest capital cost and annual $\mathrm{O}+\mathrm{M}$ cost; this combined with the low roundtrip efficiency make this option not economically viable. A cost reduction is required in order for storage to be implemented at 
a distribution network scale in preference to network reinforcement.

\section{CONCLUSIONS}

This paper has presented a brief overview of energy storage technologies and their suitability for use within electrical power networks. Detailed analyses have been carried out to demonstrate the (in many cases, limited) viability of several candidate storage types, based on two different financial modeling techniques. The first method involved a customerbased analysis of ubiquitous storage implementation, involving peak-clipping and valley-filling in conjunction with real-time pricing signals. The second method calculated the benefits and costs of utilizing storage at or near intermittent generation sites to improve the combined load factor of the generator plus storage device. This was compared with the capital cost of network upgrading to accommodate higher peak generation power output with low capacity factor.

The results of the studies show that, in the short to medium term, the cost of electrical storage remains too high to be viable. The limiting factors for hydrogen-based solutions are the capital cost, technical complexity and low electrical roundtrip efficiency. Battery storage is limited by both initial capital outlay and the ongoing maintenance cost. Both these options also present safety hazards that would have to be considered carefully in any proposed domestic-scale implementations. Of the two, battery storage appears the most viable, but neither is currently cheaper than conventional network upgrades. Unless the price structure of electrical power changes radically, or a step technological advance occurs, these solutions are unlikely to be widespread in the short to medium term and instead remain in the realm of "future power systems".

Storage of thermal energy in reservoirs such as hot or cold water tanks does appear to present a feasible solution in the near-term. Thermal storage is particularly suitable to the domestic environment since the technology is simple, established, cheap, safe, and of high efficiency. The efficiency is high in the domestic environment because the stored energy can be used locally within the same building

There is potential for substantial further work in this field. Aside from storage technology improvements, there is considerable scope for development of the simulation tools used in this paper, to allow more accurate analysis of storage effects, and to verify or validate the results. The methods of controlling ubiquitous storage also require investigation. Candidate methods include centralized, distributed and pricing control mechanisms, and quite possibly a mix of all three.

\section{REFERENCES}

[1] C. Flavin, "Energy for the 21st Century", April 1999, World Bank Energy Week

[2] A. Roscoe, "Demand response and embedded storage to facilitate diverse and renewable power generation portfolios in the UK", MSc dissertation, University of Strathclyde, 2004, http://ftp.strath.ac.uk/Esru_public/documents/MSc_2004/roscoe.pdf

[3] DTI \& EA Technology, "Review of electrical energy storage technologies and systems and of their potential for the UK", 2004, www.dti.gov.uk/renewables/publications/pdfs/dgdt1000500000.pdf
[4] DTI and UMIST, "The future value of electrical energy storage in the UK with generator intermittency", 2004, www.dti.gov.uk/renewables/publications/pdfs/dgdt100400000.pdf

[5] A. King and W. Knight, Uninterruptible Power Supplies, McGraw-Hill, 2003, pp. 223-229.

[6] A.Korbik, S.D.J. McArthur, G.W.Ault, G.M.Burt, J.R.McDonald, "Enabling Active Distribution Networks Through Decentralised Autonomous Network Management”, 18th International Conference on Electricity Distribution (CIRED), 6-9 June 2005, Turin, Italy

[7] M.Thoma, I.Wasiek, C.Foote, "A Power Quality Management Algorithm for Low Voltage Grids with Distributed Resources", DISPOWER Project Highlight No.17, 2005, www.dispower.org

[8] A. Cruden and G.J.W. Dudgeon, "Opportunities for Energy Storage Devices operating with Renewable Energy Systems", Electric Energy Storage Applications and Technologies (EESAT) 2000, 18-20 September 2000, Orlando, Florida

[9] T.Chandarsupsang, "An Alternative Electricity Market Architecture for an Inclusion of Distributed Generation in a Competitive Environment", PhD Thesis, 2005, University of Strathclyde

[10] DTI, Energy statistics, 2004, www.dti.gov.uk/energy/

[11] ESRU, ESP-r modelling tool, 2004, University of Strathclyde, www.esru.strath.ac.uk

[12] M. J. Khan, M. T. Iqbal, "Pre-Feasibility Study of Stand-alone Hybrid Energy Systems for Applications in Newfoundland", Renewable Energy 30, P835-854, 2005

[13] P. Espie, C. Foote, G. W. Ault, J. R. McDonald, 2002, "A Multiple Criteria Model for Evaluating Distributed Generation Development Options", International Symposium on Distributed Generation: Power System and Market Aspects, Stockholm, Sweden

\section{BIOGRAPHIES}

Colin E.T. Foote is a Research Fellow at the Institute for Energy and Environment at the University of Strathclyde. He graduated in 1999 with a Masters degree in Electronic and Electrical Engineering with Business Studies and is currently working towards a $\mathrm{PhD}$. His research interests include power system modeling, simulation and analysis, decision support methods, distribution network planning, distributed generation and wind power.

Andrew J. Roscoe received the B.A. degree in Electrical and Information Sciences Tripos at Pembroke college, Cambridge, England in 1991. He worked in the fields of radar and RF communications for 12 years. He was awarded an MSc from the University of Strathclyde in 2004 and subsequently joined the Institute for Energy and Environment as a research fellow, working in the field of distributed generation.

Robert A.F. Currie received his BEng and MSc degrees from the University of Strathclyde in 2001 and 2002 respectively. He is currently working towards his $\mathrm{PhD}$ within the Institute for Energy and Environment. His research interests are active management of distribution networks and distributed and renewable generation.

Graham W. Ault graduated from the University of Strathclyde in 1993 with a first class honours degree in Electrical and Mechanical Engineering. $\mathrm{He}$ returned to the Institute for Energy and Environment in 1996 to fill a $\mathrm{PhD}$ research post focusing on the impact of small-scale generation on electricity networks. Gaining his $\mathrm{PhD}$ in 2000 he has expanded his research portfolio to span several aspects of distributed generation, asset management, and power system planning and development.

James R. McDonald received his $\mathrm{BSc}$, MSc and $\mathrm{PhD}$ degrees from Strathclyde University. He was appointed as a lecturer within the Department of Electronic and Electrical Engineering at Strathclyde University in 1984. His research activities lie in the areas of: Power System Protection and Measurement; Artificial Intelligence Applications in Power Engineering; Energy Management. He has published over 100 technical papers and is coauthor of two books. He is currently the Rolls-Royce Professor of Power Engineering, the Director of the Institute for Energy and Environment, and the Head of the Department of Electronic and Electrical Engineering at Strathclyde University. 